\title{
Autonomic nervous system dysfunction in children with severe tetanus: dissociation of cardiac and vascular sympathetic control
}

\section{C.A. Mazzei de Davila, D.F. Davila, \\ J.H. Donis and X. Gonzalo}

\author{
Unidad de Cuidados Intensivos Pediátricos, Departamento de Pediatría, \\ Instituto de Investigaciones Cardiovasculares, Universidad de Los Andes, \\ Mérida, Venezuela
}

\section{Correspondence}

C.A. Mazzei de Davila

Unidad de Cuidados Intensivos

Pediátricos

Apartado Postal 590

Mérida

Venezuela

Fax: +58-27-4240-3203

E-mail: carmd@ing.ula.ve

Research supported by $\mathrm{CDCH}-\mathrm{T}$ and ULA M-596-97-07-D.

Received February 4, 2002

Accepted March 18, 2003

\begin{abstract}
The medical records of ten pediatric patients with a clinical diagnosis of tetanus were reviewed retrospectively. The heart rate and blood pressure of all tetanus patients were measured noninvasively every hour during the first two weeks of hospitalization. Six of ten tetanus patients presented clinical evidence of sympathetic hyperactivity (group A) and were compared with a control group consisting of four children who required mechanical ventilation for diseases other than tetanus (group B). Heart rate and blood pressure simultaneously and progressively increased to a maximum by day 7 . The increase over baseline was $43.70 \pm 11.77 \mathrm{bpm}($ mean $\pm \mathrm{SD})$ for heart rate $(\mathrm{P}<0.01)$ and 38.60 $\pm 26.40 \mathrm{mmHg}$ for blood pressure $(\mathrm{P}<0.01)$. These values were higher and significantly different from those of the control group (group B) at day 6 , which had an average heart rate increase over baseline of 19.35 $\pm 12.26 \mathrm{bpm}(\mathrm{P}<0.05)$ and blood pressure of $10.24 \pm 13.30 \mathrm{mmHg}$ $(\mathrm{P}<0.05)$. By the end of the second week of hospitalization, in group A the increase of systolic blood pressure over baseline had diminished to $9.60 \pm 15.37 \mathrm{mmHg}(\mathrm{P}<0.05)$, but the heart rate continued to be elevated $(27.80 \pm 33.92 \mathrm{bpm}, \mathrm{P}=\mathrm{NS})$, when compared to day 7 maximal values. The dissociation of these two cardiovascular variables at the end of the second week of hospitalization suggests the presence of asymmetric cardiac and vascular sympathetic control. One possible explanation for these observations is a selective and delayed action of tetanus toxin on the inhibitory neurons which control sympathetic outflow to the heart.
\end{abstract}

Key words

- Tetanus patients

- Sympathetic control

- Autonomic dysfunction

- Blood pressure

- Heart rate
Autonomic nervous system involvement in patients with tetanus was initially reported by Danish investigators in 1954 (1). The first detailed description of the heart rate and blood pressure abnormalities of patients with autonomic dysfunction secondary to tetanus was provided by Kerr et al. in 1968 (2).
Several clinical investigations have emphasized that sinus tachycardia and systemic hypertension begin simultaneously and are still present at the end of the first two weeks of hospitalization (3). Most studies conclude that these cardiovascular abnormalities are due to hyperactivity of the sympathetic ner- 
vous system $(4,5)$. Nonetheless, how these cardiovascular abnormalities evolve is not well defined $(6,7)$.

In the present retrospective investigation, we reviewed the medical records of ten children who were admitted to the Intensive Care Unit (ICU) of the University of Los Andes Hospital with a clinical diagnosis of tetanus during the period from January 1982 to December 1995. The diagnosis of severe tetanus with autonomic dysfunction was based on the presence of generalized muscular spasms, sinus tachycardia and systemic hypertension (3). All patients were admitted within $24 \mathrm{~h}$ of the beginning of the muscle spasms. Mean age was $8 \pm 3.36$ years (range 2 to 13 years) and sex was equally distributed.

All patients required sedation with diazepam, 2-3 mg kg-1 $24 \mathrm{~h}^{-1}$, intubation and mechanical ventilation (pancuronium, $100 \mu \mathrm{g} / \mathrm{kg}$ per dose). The autonomic crisis was treated as follows: 1) patients admitted between 1982 and 1985 received morphine, $1 \mathrm{mg} / \mathrm{kg}$ per dose (4-6 doses per day), propranolol, 2-7 $\mathrm{mg} \mathrm{kg}^{-1} 24 \mathrm{~h}^{-1}$, and magnesium sulfate, $1 \mathrm{mEq} \mathrm{kg}{ }^{-1} 24 \mathrm{~h}^{-1}$. 2) Patients admitted after 1987 were given morphine, $0.1 \mathrm{mg} / \mathrm{kg}$ per dose (4-6 doses per day), labetalol, 2-8 mg $\mathrm{kg}^{-1} 24 \mathrm{~h}^{-1}$, and magnesium sulfate, $1 \mathrm{mEq}$ $\mathrm{kg}^{-1} 24 \mathrm{~h}^{-1}$.

In patients admitted before 1985 , the heart rate was determined hourly with electrocardiographic monitors and blood pressure was measured with a mercury sphygmomanometer and appropriate pediatric blood pressure cuffs. Systolic and diastolic blood pressures were estimated according to phases one and four of the Korotkoff method, respectively (8). Patients admitted between 1985 and 1995 were monitored by the oscillometric technique using a DINAMAPTM adult/pediatric vital signs monitor model 845XT (Tampa, FL, USA).

The control group consisted of four patients with diseases other than tetanus (group B) aged $9 \pm 4$ years, range 3 to 13 years, who had required mechanical ventilation and muscle relaxants for causes other than tetanus. These patients had severe head trauma, required mechanical ventilation, muscle relaxants (pancuronium, $100 \mu \mathrm{g} / \mathrm{kg}$ per dose), analgesia (meperidine $1 \mu \mathrm{g} / \mathrm{kg}$ per dose, every $6 \mathrm{~h}$ ), and diuretics (furosemide, $0.5 \mathrm{mg} / \mathrm{kg}$ per dose, every $12 \mathrm{~h}$ ) and remained in the ICU for 5 to 7 days. Simultaneous hospitalization, medical care provided by the same physician, and heart rate and blood pressure increases above pre-established limits were used as inclusion criteria. This retrospective clinical investigation was approved by the Commission for Scientific Studies of the University of Los Andes. Informed consent was obtained from the children's parents.

The highest values for blood pressure and heart rate were obtained for all tetanus patients from the hourly measurements made each day. The absolute increase in heart rate and blood pressure was determined from the difference between the latter values and preestablished maximal limits (95th percentile for age and sex) $(9,10)$. The highest blood pressure and heart rate changes observed in patients with diseases other than tetanus were obtained and assessed similarly. Values are reported as means $\pm \mathrm{SD}$. Intragroup and intergroup comparisons were performed by the Friedman paired test for series of interdependent variables, with the level of significance set at $\mathrm{P}<0.05$ (11).

Based on heart rate and blood pressure measurements, six patients showed increases above the pre-established limits (95th percentile for age and sex) and were considered to have clinical evidence of sympathetic hyperactivity (group A). In group A, one patient had sinus tachycardia but the blood pressure did not increase above the 95th percentile for age and sex (3).

As can be seen in Figure 1, by day 1 of hospitalization, group A patients had absolute heart rate and blood pressure values already above the pre-established limits, 95th percentile for age and sex, which progressively increased to a maximum by day 7 
(Table 1 and Figure 1). These values were significantly different from those recorded during the first 4 days. Moreover, when the maximum absolute increases recorded on day 7 were compared to those of the patients with mechanical ventilation for causes other than tetanus at day 6 (group B - systolic pressure: $10.24 \pm 13.30 \mathrm{mmHg}$; heart rate: $19.35 \pm 12.26 \mathrm{bpm}$ ), patients with tetanus (group A) had significantly larger increases in heart rate $(43.70 \pm 11.77 \mathrm{bpm}, \mathrm{P}<0.05)$ and systolic blood pressure $(38.60 \pm 26.40$ $\mathrm{mmHg}, \mathrm{P}<0.05$ ) (Table 2). During the second week of hospitalization, the heart rate decreased slightly but not significantly from day 7 to day 9 . It then became stationary and continued to be elevated. In contrast, the systolic and diastolic blood pressures decreased gradually and significantly (Table 1 and Figure 1). In other words, although the heart rate and blood pressure rose simultaneously at the beginning of the autonomic crisis, these two cardiovascular variables became dissociated by the end of the second week of hospitalization. It should be emphasized that metabolic and respiratory parameters were kept at physiological levels throughout the period of hospitalization (3). All patients with severe tetanus and autonomic dysfunction survived and were subsequently discharged from the hospital.

The hyperadrenergic syndrome that occurs in tetanus is characterized by hypertension, tachycardia and increased cardiac index. Hemodynamic studies during the management of severe tetanus with autonomic dysfunction have shown that systemic hypertension is due to a high output circulatory state with increased cardiac index and normal to low peripheral vascular resistance (12). These cardiovascular abnormalities are paralleled by marked increases in serum catecholamine concentration (13). Moreover, spectral analysis of heart rate variability has demonstrated unopposed sympathetic nervous system hyperactivity and decreased parasympathetic modulation of cardiac

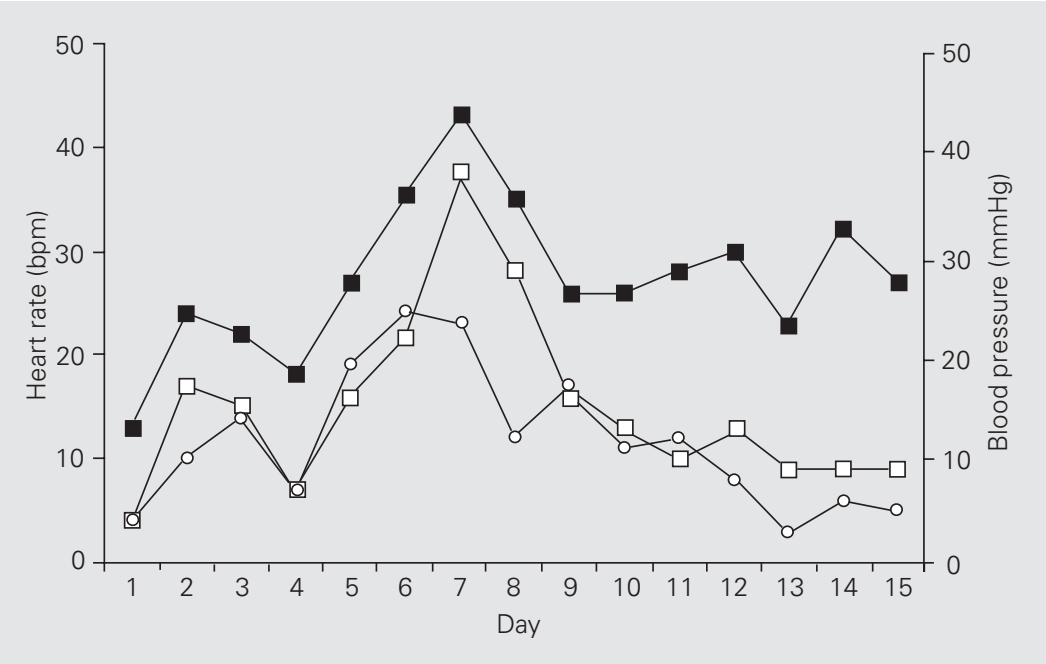

Figure 1. Heart rate and blood pressure changes in children with severe tetanus and autonomic dysfunction. Heart rate and blood pressure increased simultaneously and progressively to a maximum by day 7 . The heart rate (filled squares) decreased slightly but not significantly from day 7 to day 9 . It then became stationary and persisted elevated thereafter. In contrast, the systolic (open squares) and diastolic pressures (circles) decreased gradually and significantly until day 15. Data are reported as increases above the 95th percentile for age and sex. Standard errors were omitted for purposes of clarity in constructing the figure.

Table 1. Heart rate and blood pressure changes in children with severe tetanus and autonomic dysfunction.

\begin{tabular}{|c|c|c|c|}
\hline \multirow[t]{2}{*}{ Day } & \multirow{2}{*}{$\begin{array}{l}\text { Heart rate } \\
\text { (bpm) }\end{array}$} & \multicolumn{2}{|c|}{ Blood pressure (mmHg) } \\
\hline & & Systolic & Diastolic \\
\hline 1 & $13.20 \pm 17.99$ & $4.50 \pm 7.00$ & $4.33 \pm 7.50$ \\
\hline 2 & $24.10 \pm 26.97$ & $17.50 \pm 13.50$ & $10.50 \pm 7.80$ \\
\hline 3 & $22.10 \pm 20.10$ & $15.60 \pm 14.80$ & $14.00 \pm 15.90$ \\
\hline 4 & $18.20 \pm 18.03$ & $7.30 \pm 11.00$ & $7.50 \pm 6.66$ \\
\hline 5 & $27.20 \pm 19.59$ & $16.50 \pm 14.80$ & $19.50 \pm 27.75$ \\
\hline 6 & $36.70 \pm 19.54$ & $22.16 \pm 15.70$ & $24.33 \pm 23.65^{* *}$ \\
\hline 7 & $43.70 \pm 11.77^{*}$ & $38.60 \pm 26.40^{+}$ & $23.83 \pm 18.91$ \\
\hline 8 & $35.40 \pm 17.05$ & $28.50 \pm 20.20$ & $12.50 \pm 15.58$ \\
\hline 9 & $26.20 \pm 20.97$ & $16.16 \pm 10.70$ & $17.50 \pm 23.60$ \\
\hline 10 & $26.20 \pm 18.01$ & $13.33 \pm 14.88$ & $11.00 \pm 9.49$ \\
\hline 11 & $28.50 \pm 15.97$ & $10.16 \pm 11.34$ & $12.00 \pm 17.38$ \\
\hline 12 & $30.05 \pm 15.55$ & $13.33 \pm 14.88$ & $8.00 \pm 12.72^{\#}$ \\
\hline 13 & $23.03 \pm 23.48$ & $9.16 \pm 16.12$ & $3.66 \pm 7.01$ \\
\hline 14 & $32.60 \pm 24.49$ & $9.66 \pm 15.54$ & $6.00 \pm 11.42$ \\
\hline 15 & $27.80 \pm 33.92$ & $9.60 \pm 15.37$ & $5.64 \pm 9.83$ \\
\hline
\end{tabular}

Values are reported as means \pm SD of increases for a given day compared to the previous day.

${ }^{*} P<0.01$ only compared to days $1-4 .+P<0.05$ compared to days $1-4$ and days $9-15$. * $P<0.05$ compared to days 1, 2, 3 and 5 . \#P<0.01 compared to days 13-15 (Friedman paired test for series of interdependent variables). 
rhythm (14).

In the present retrospective investigation, we found that the changes in heart rate and blood pressure of children with severe tetanus were dissociated by the end of the second week of hospitalization. The blood pressure gradually returned to normal, while the heart rate persisted accelerated. Since tachycardia and hypertension are both secondary to sympathetic hyperactivity, one would expect these two cardiovascular variables to behave similarly at the end of the autonomic crisis. This unexpected finding raises several pertinent questions: 1) Is this persistent sinus tachycardia the expression of an undetected metabolic derangement or sepsis? 2) Could instrumentation, medical care and the use of multiple medications be responsible for the observed phenomena? 3) Could our findings be due to a selective and delayed action of tetanus toxin on the neurons, which use the inhibitory neurotransmitter gammaaminobutyric acid (GABA) to control sympathetic preganglionic outflow to the heart (15)? On the basis of the last hypothesis, the potentiated chronotropic response and normal or blunted vasomotor response would indicate a dissociation of cardiac and vascular sympathetic control (16). Our patients with severe tetanus (group A) received muscle relaxants, morphine and beta-blockers throughout the two-week observation period and their clinical, metabolic and respiratory parameters were under constant monitoring. The presence of undetected metabolic derangement secondary to acute renal failure probably induced by sympathetic overactivity (17) or sepsis is unlikely. Patients with diseases other than tetanus (group B) were similarly instrumented, received the same muscle relaxants and were cared for by the same physician. Moreover, since group A patients were receiving beta-adrenergic blockers and yet, the highest values of heart rate and blood pressure of group B patients were still significantly lower, a state of primary and unusually intense cardiac and peripheral sympathetic activation must have been present in group A.

Tetanus toxin experimentally injected into skeletal muscle is taken up and concentrated by terminal varicosities within pre- and paravertebral sympathetic ganglia (3). More recently, using the novel technique of neuroanatomic tracing, tetanus toxin was shown to be retrogradely transported to the GABAergic terminals, which synapse on the sympathetic preganglionic neurons of the last cervical and first three thoracic spinal cord segments (18). Since experimental stimulation of these spinal pathways, under specific physiological or pathological conditions $(15,19,20)$, can increase or decrease heart rate, a selective and delayed action of tetanus toxin on these sympathetic pathways could be responsible for our findings.

Table 2. Heart rate and systolic pressure changes in children with autonomic dysfunction secondary to tetanus and in children with diseases other than tetanus (non-tetanus).

\begin{tabular}{lccrrr}
\hline Day & \multicolumn{2}{c}{ Tetanus $(\mathrm{N}=6)$} & \multicolumn{2}{c}{ Non-tetanus $(\mathrm{N}=4)$} \\
\cline { 2 - 3 } \cline { 5 - 6 } & $\begin{array}{c}\text { Heart rate } \\
(\mathrm{bpm})\end{array}$ & $\begin{array}{c}\text { Systolic blood pressure } \\
(\mathrm{mmHg})\end{array}$ & & $\begin{array}{c}\text { Heart rate } \\
(\mathrm{bpm})\end{array}$ & $\begin{array}{c}\text { Systolic blood pressure } \\
(\mathrm{mmHg})\end{array}$ \\
\hline 6 & $36.70 \pm 19.45^{*}$ & $22.16 \pm 15.70^{+}$ & & $19.35 \pm 12.26$ & $10.24 \pm 13.30$ \\
7 & $43.70 \pm 11.77^{*}$ & $38.60 \pm 26.40^{+}$ & & $9.08 \pm 15.54$ & $7.60 \pm 12.54$ \\
8 & $35.40 \pm 35.17^{*}$ & $28.50 \pm 20.20^{+}$ & & $16.87 \pm 27.01$ & $3.60 \pm 3.60$ \\
\hline
\end{tabular}

Data are reported as means \pm SD and represent increases over pre-established limits.

${ }^{*} P<0.05$ compared to heart rate of the non-tetanus children. ${ }^{+} P<0.05$ compared to systolic pressure of the non-tetanus children (Friedman paired test for series of interdependent variables). 
Finally, experimental and clinical prospective studies should be done in order to understand the role of tetanus toxin in the activa-

\author{
tion of the sympathetic nervous system and \\ in the dissociation of cardiac and vascular \\ control.
}

\section{References}

1. Bjornboe M, Ibsen B \& Johnson S (1954). Tetanus. A case treated with artificial respiration during 17 days. Danish Medical Bulletin, 1: 129-131.

2. Kerr JH, Corbett JL, Prys-Roberts C, Smith AC \& Spalding JM (1968). Involvement of the sympathetic nervous system in tetanus. Studies on 82 cases. Lancet, 2: 236-241.

3. Cook TM, Protheroe RT \& Handel JM (2001). Tetanus: a review of the literature. British Journal of Anaesthesia, 87: 477-487.

4. Kerr JH, Corbett JL \& Spalding JMK (1968). Sympathetic overactivity in tetanus. Proceedings of the Royal Society of Medicine, 62: 659662.

5. Domenighetti GM, Savary G \& Stricker H (1984). Hyperadrenergic syndrome in severe tetanus: extreme rise in catecholamines responsive to labetalol. British Medical Journal, 288: 1483-1484.

6. Peetermans WE \& Schepens D (1996). Tetanus - still a topic of present interest: a report of 27 cases from a Belgian hospital. Journal of Internal Medicine, 239: 249-252.

7. Bhagwanjee S, Bosenberg AT \& Muckart DJJ (1999). Management of sympathetic overactivity in tetanus with epidural bupivacaine and sufentanil: Experience with 11 patients. Critical Care Medicine, 27: 1721-1725.

8. Moss AJ (1978). Indirect methods of blood pressure measurement. Pediatric Clinics of North America, 25: 3-14.

9. Report of the Second Task Force on Blood Pressure Control in Children (1987). Task Force on Blood Pressure Control in Children. National Heart, Lung, and Blood Institute, Bethesda, Maryland. Pediatrics, 79: 1-25.

10. Morgenstern BZ (1994). Hypertension in pediatric patients: Current issues. Mayo Clinic Proceedings, 69: 1089-1097.

11. Glantz SA (1992). Primer of Biostatistics. McGraw Hill Inc., Toronto, Canada, 358-359.

12. Udwadia FE, Sunavala JD, Jain MC, D'Costa JR, Jain PK, Lall A, Sekhar M, Udwadia ZF, Kapadia F \& Kapur KC (1992). Hemodynamic studies during the management of severe tetanus. Quarterly Jour- nal of Medicine, 302: 449-460

13. Kanerek DJ, Kaufman B \& Zwi S (1973). Severe sympathetic hyperactivity associated with tetanus. Archives of Internal Medicine, 276 : 447-460.

14. Goto T, Fukushima H, Sasaki G, Matsuo N \& Takahashi T (2001). Evaluation of autonomic nervous function with spectral analysis of heart rate variability in a case of tetanus. Brain Development, 23: 791-795.

15. Korner PI (1979). Central nervous system control of autonomic cardiovascular function. In: Berne RM, Sperelakis N \& Geiger SR (Editors), Handbook of Physiology, The Cardiovascular System I, The Heart. American Physiological Society, Bethesda, MD, USA, 691739.

16. Furlan R, Jacob G, Snell M, Robertson D, Posta A, Harris P \& Mosqueda-Garcia R (1998). Chronic orthostatic intolerance: a disorder with discordant cardiac and vascular sympathetic control. Circulation, 98: 2154-2159.

17. Daher E, Abdulkhader RCRM, Motti E, Marcondes M, Sabbaga E \& Burdmann EA (1997). Prospective study of tetanus-induced acute renal dysfunction: role of adrenergic overactivity. American Journal of Tropical Medicine and Hygiene, 57: 610-614.

18. Logorio MA, Akmentin W, Gallery F \& Cabot JB (2000). Ultrastructural localization of the binding fragment of tetanus toxin in putative gamma-aminobutyric acidergic terminals in the intermediolateral cell column: A potential basis for sympathetic dysfunction in generalized tetanus. Journal of Comparative Neurology, 419: 471-484.

19. Norris JE, Foreman RD \& Wurster RD (1974). Responses of the canine heart to stimulation of the first five ventral thoracic roots. American Journal of Physiology, 227: 9-12.

20. Gatti PJ, Johnson TA \& Massari VJ (1996). Can neurons in the nucleus ambiguous selectively regulate cardiac rate and atrio-ventricular conduction. Journal of the Autonomic Nervous System, 75: 123-127. 